Scientific Electronic Archives

Issue ID: Sci. Elec. Arch. Vol. 15 (1)

January 2022

DOI: http://dx.doi.org/10.36560/15120221491

Article link: https://sea.ufr.edu.br/SEA/article/view/1491

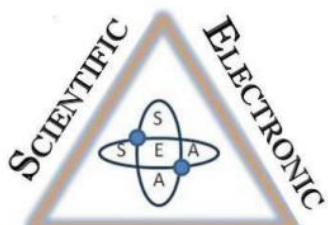

ArChIVES

ISSN 2316-9281

\title{
Produção de variedades de alface destinadas ao processamento mínimo
}

\author{
Production of lettuce varieties intended for minimal processing
}

\author{
Abadia dos Reis Nascimento \\ Universidade Federal de Goiás \\ Corresponding author \\ Cristiane Maria Ascari Morgado \\ Universidade Estadual de Goiás \\ cristianemorgado4@yahoo.com.br \\ Fernanda Campos de Oliveira Aguiar \\ Universidade Federal de Goiás \\ Igor Galvão Santana \\ Universidade Federal de Goiás \\ Izadora Neves Lago \\ Universidade Federal de Goiás \\ Ana Carolina Martins Moura \\ Universidade Federal de Goiás \\ Luis Carlos Cunha Junior \\ Universidade Federal de Goiás
}

\begin{abstract}
Resumo. Este trabalho teve como objetivo estudar diferentes variedades de alface do tipo americana e seu potencial para a produção de produtos minimamente processados. O experimento foi conduzido na Horta do Setor de Horticultura, da Escola de Agronomia, na Universidade Federal de Goiás, em solo classificado como Latossolo. As variedades de alface analisadas foram: 'Amélia'; 'Lucy Brown'; 'Laurel'; '5007' e '5010'. As mudas foram avaliadas quanto à taxa de germinação, peso total, peso das folhas, peso da raiz, tamanho da maior raiz, altura e largura da folha maior, altura total da muda, quantidade de folhas. A colheita foi realizada 40 dias após o transplante, sendo coletadas 10 cabeças de alface de cada variedade e de cada bloco e levadas ao laboratório para avaliação. O delineamento experimental utilizado foi o de blocos casualizados, utilizando-se 4 blocos com todas as variedades (parcela), sendo cada parcela constituída por 140 plantas para cada variedade. As cabeças de alface colhidas foram avaliadas quanto ao peso total da planta, da raiz e da parte comercial, além da porcentagem do peso da parte comercial em relação ao peso total da planta. As alfaces de cada variedade que se apresentavam em condições comerciais foram colhidas, armazenadas em caixas plásticas e transportadas para uma empresa de processamento mínimo de alimentos. $O$ delineamento experimental foi o inteiramente casualizado, utilizando-se 3 repetições para cada variedade. As avaliações dos teores de acidez titulável, sólidos solúveis e ácido ascórbico foram realizadas a cada dois dias, totalizando 6 dias de armazenamento. As variedades 5007 e 5010 são recomendadas para plantio e processamento mínimo, visto que apresentaram melhor desempenho quanto aos parâmetros avaliados.

Palavras-chaves Lactuca sativa, produtividade, refrigeração, pós-colheita.
\end{abstract}

Abstract. This work aimed to study different varieties of lettuce and their potential for the production of minimally processed products. The experiment was conducted in the Horta do Setor de Horticulture, School of Agronomy, Federal University of Goiás, in soil classified as Latosol. The lettuce varieties analyzed were: 'Amelia'; "Lucy Brown"; 'Laurel'; 
'5007' and '5010'. The seedlings were evaluated for germination rate, total weight, leaf weight, root weight, size of the largest root, height and width of the largest leaf, total height of the seedling, number of leaves. Harvesting was carried out 40 days after transplanting, with 10 heads of lettuce of each variety and block being collected and taken to the laboratory for evaluation. The experimental design used was a randomized block design, using 4 blocks with all varieties (plot), with each plot consisting of 140 plants for each variety. The harvested heads of lettuce were evaluated for the total weight of the plant, the root and the commercial part, in addition to the percentage of the commercial part weight in relation to the total weight of the plant. Lettuces of each variety that were available under commercial conditions were harvested, stored in plastic boxes and transported to a minimal food processing company. The experimental design was completely randomized, using 3 replications for each variety. The evaluations of titratable acidity, soluble solids and ascorbic acid contents were carried out every two days, totaling 6 days of storage. The varieties 5007 and 5010 are recommended for planting and minimal processing, as they performed better in terms of the evaluated parameters.

Keywords: Lactuca sativa, productivity, refrigeration, post-harvest.

\section{Introdução}

O setor de hortaliças do Brasil é altamente produtivo, mas devido à fragilidade na pós-colheita, cerca de 35 a $45 \%$ destes produtos são perdidos ou desperdiçados, desde a classificação e seleção das olerícolas na propriedade rural até o consumo final (Tofanelli et al., 2009). Dentre as hortaliças de grande consumo, a alface é a sexta hortaliça em importância econômica e oitava em termos de volume produzido (Biasi et al., 1991).

Seu cultivo apresenta limitações, principalmente em virtude de sensibilidade às condições adversas de temperatura, umidade do ar e chuva (Gomes et al., 2005). Por ser uma cultura de alta perecibilidade, é importante que se conheça e utilize as práticas adequadas de manuseio durante as fases de colheita, pós-colheita, armazenamento, transporte, distribuição, comercialização e consumo (Freitas-Silva et al., 2013), e o manejo inadequado provoca redução da vida de prateleira e aumento do custo final do produto para o consumidor (Álvares et al., 2007).

O cultivo da alface usualmente se dá em canteiros fazendo uso, principalmente, da irrigação por aspersão convencional. No entanto, com o avanço no desenvolvimento da plasticultura, seu cultivo em túneis plásticos e estufas expandiu. Outro método alternativo é o de irrigação localizada, dentre eles 0 gotejamento. Porém deve-se conhecer o manejo adequando da água utilizada na irrigação para que bons resultados sejam alcançados.

No Brasil, a principal forma de comercialização da alface é in natura, acondicionada em engradados. Todavia, o mercado torna-se cada vez mais exigente, necessitando de formas de comercialização mais convenientes aos consumidores, mas que mantenham a qualidade do vegetal (Galati et al., 2015). Assim, o processamento mínimo vem ganhando espaço, mas para que isso ocorra, é essencial que a qualidade pós-colheita, no que se refere a aspectos como aparência, qualidade sensorial e valor nutritivo (Azevedo et al., 2015), sejam mantidos. Para isso, deve-se existir um controle da temperatura à qual o produto é exposto durante 0 manuseio $e$ armazenamento. O retardo no resfriamento dos vegetais após a colheita pode reduzir sua qualidade e vida útil (Chitarra \& Chitarra, 2005).
O processamento mínimo de frutas e hortaliças é definido como a técnica pela qual os vegetais sofrem alterações físicas, ou seja, foram descascados, picados, torneados e ralados, dentre outros processos, mantendo-os no estado fresco e metabolicamente ativos (Mattos et al., 2007).

A alface destaca-se entre as hortaliças folhosas mais consumidas por conta da sua importância alimentar como fonte de vitaminas e sais minerais (Santi et al., 2010), pois apresenta em sua composição folato, boa quantidade de betacaroteno, vitamina $C$, potássio e certos fitoquímicos, como os flavonoides e lactucina (Chitarra \& Chitarra, 2005).

Para que a conservação pós-colheita de produtos vegetais ocorra, as condições ambientais podem ser obtidas através do controle de temperatura, da circulação de ar e da umidade relativa. Assim, os principais objetivos do armazenamento são a redução da atividade biológica do produto e a redução do crescimento de microrganismos, a partir de baixas temperaturas, bem como a redução na transpiração, pela diminuição das diferenças entre a temperatura do ar e a do produto (Chitarra \& Chitarra, 2005).

A preservação da qualidade da alface na pós-colheita pode ser obtida a partir da atmosfera modificada (AM). Nesse tipo de armazenamento, a atmosfera ambiente é alterada pelo uso de filmes plásticos, proporcionando o aumento da concentração de $\mathrm{CO}_{2}$ e diminuição de $\mathrm{O}_{2}$, com o processo respiratório. $\mathrm{Na} \mathrm{AM}$, as concentrações de $\mathrm{O}_{2}$ e $\mathrm{CO}_{2}$ não são controladas, e variam com o tempo, temperatura, tipo de filme e com a taxa respiratória do produto (Chitarra \& Chitarra, 2005). Este método, além de proporcionar redução da atividade respiratória, aumenta a umidade relativa e assim, diminui a perda de água por transpiração, e consequentemente o murchamento (Amarante et al., 2001).

Diante do exposto, o objetivo desse trabalho foi estudar diferentes variedades de alface do tipo americana e seu potencial para produção de produtos minimamente processados.

\section{Material e Métodos}

Parte I: Experimento de Campo

O experimento foi conduzido na Horta do Setor de Horticultura, da Escola de Agronomia, Universidade Federal de Goiás, em solo 
classificado como Latossolo. O município de Goiânia está situado a 16³5'12"de Latitude Sul e 4921'14 de Longitude Oeste e altitude de $749 \mathrm{~m}$. O clima da região, de acordo com Köeppen é Aw, tropical com estação seca, com duas estações bem definidas: uma chuvosa, que vai geralmente de outubro a abril, e uma seca, de maio a setembro.

As variedades de alface analisadas foram: 'Amélia'; 'Lucy Brown'; 'Laurel'; '5007' e '5010'. São alfaces do tipo americana, sendo consideradas plantas de tamanho grande e vigor elevado. Suas folhas mais espessas ajudam a proteger a cabeça. Quanto ao ciclo médio, a partir do transplantio é de 45 a 55 dias e após o semeio é de 85 a 90 dias. As variedades apresentam coloração verde clara.

$\mathrm{Na}$ fase de produção de mudas foram utilizadas bandejas descartáveis de poliestireno expandido com 288 células. O substrato comercial utilizado foi o Carolina Soil, isento de pragas e doenças, sendo, portanto, indicado para produção de mudas de hortaliças.

O preparo da área consistiu em duas gradagens e levantamento de canteiros. Os canteiros foram preparados com dimensão de 54 $\mathrm{m}^{2}$.

A cultura foi estabelecida por transplante direto em canteiros, medindo cada um 25,00 m de comprimento, 1,00 $\mathrm{m}$ de largura e 0,20 m de altura, distanciados $0,4 \mathrm{~m}$ uns dos outros. $\mathrm{O}$ espaçamento entre as plantas foi de $7 \times 10 \mathrm{~cm}$, já que o mulching utilizado já era perfurado com essas medidas. $\mathrm{Na}$ adubação de plantio foram incorporados $0,1 \mathrm{~m}^{3}$ de esterco de gado em cada canteiro. Também foi incorporado ao solo o adubo químico NPK 4-30-10, aplicando-se $0,187 \mathrm{~g} \mathrm{~m}^{-2}$. O transplantio foi realizado 22 dias após semeadura, quando as mudas apresentavam de quatro a seis folhas definitivas. Houve reposição das mudas mortas até 4 dias após o plantio.

Nos primeiros 15 dias foram efetuadas irrigações por gotejamento, uma pela manhã e outra à tarde, de forma a manter o teor de água no solo próximo à capacidade de campo. Após os 15 dias, a irrigação foi feita duas vezes pela manhã, e três vezes à tarde. A adubação de cobertura foi realizada 12 dias após o transplantio, utilizando-se o adubo químico NPK da Hortimax 13-3-25. Duas semanas após, foi realizada a adubação foliar com os seguintes elementos e suas concentrações: Avant C4 diluindo-se $33 \mathrm{~mL}$ em $10 \mathrm{~L}$ de água, para cada canteiro. Componentes: $\mathrm{N}-3 \% 38,7 \mathrm{~g} / \mathrm{L} ; \mathrm{P}_{2} \mathrm{O}_{5-}$ $5 \%$ 64,5g/L; S - 2,82\% 36,37g/L; B - 0,2\% 2,58g/L; $\mathrm{Cu}-0,3 \% 3,87 \mathrm{~g} / \mathrm{L} ; \mathrm{Mn}-2 \% 25,8 \mathrm{~g} / \mathrm{L} ; \mathrm{Mo}-1 \%$ $12,9 \mathrm{~g} / \mathrm{L} ; \mathrm{Zn}-3 \% 38,7 \mathrm{~g} / \mathrm{L}$.

A colheita foi realizada 40 dias após o transplante, sendo coletadas 10 cabeças de alface de cada variedade e de cada bloco e levadas ao laboratório para avaliação.

O delineamento experimental utilizado foi o de blocos casualizados, utilizando-se 4 blocos com todas as variedades (parcela), sendo cada parcela constituída por 140 plantas para cada variedade.

\section{Parte II: Processamento mínimo}

As alfaces de cada variedade que se apresentavam em condições comerciais foram colhidas, armazenadas em caixas plásticas e transportadas para a empresa de processamento mínimo de alimentos, localizada no município de Goianápolis - GO.

As alfaces foram armazenadas em câmara fria a $12^{\circ} \mathrm{C}$ durante 12 horas, antes de serem submetidas ao processamento mínimo. Após este período, em ambiente refrigerado, elas foram selecionadas, retirando-se as folhas mais velhas e danificadas a fim de se obter melhor uniformização dos lotes de cada variedade. Em seguida, as folhas foram lavadas em água corrente para remover impurezas aderidas às folhas e retirada do calor de campo.

Posteriormente iniciou-se o processamento de cada variedade, onde as folhas foram submetidas ao corte em tiras, eliminação do excesso de água em centrifuga por 2 minutos. Os produtos minimamente processados foram acondicionados em sacos de polietileno contendo, aproximadamente 200 gramas de alface em cada, selados e transportados para o laboratório da Universidade Federal de Goiás onde foram armazenados em câmaras tipo B.O.D. a $6{ }^{\circ} \mathrm{C}$ e avaliadas a cada dois dias.

0 delineamento experimental foi 0 inteiramente casualizado, utilizando-se 3 repetições para cada variedade. Cada repetição foi constituída por uma embalagem de 20 gramas. As avaliações foram realizadas a cada dois dias, totalizando 6 dias de armazenamento.

\section{Avaliações}

As mudas foram avaliadas quanto à taxa de germinação nas bandejas. Além disso, foi realizada uma caracterização (15 mudas por variedade), ou seja: peso total, peso das folhas, peso da raiz, tamanho da maior raiz, altura e largura da folha maior, altura total da muda, quantidade de folhas.

No dia da colheita foi avaliado o peso total da planta, da raiz e da parte comercial. Também foi calculada a porcentagem do peso da parte comercial em relação ao peso total da planta. Dois dias após a colheita foi realizado a contagem de plantas que não atingiram o padrão comercial (\% Não comercial) para avaliar a quantidade de plantas comercializadas (alfaces que não formaram cabeça comercial, expressa em porcentagem em relação ao total plantado).

Os produtos minimamente processados de cada variedade foram avaliados quanto aos teores de acidez titulável, sólidos solúveis e de ácido ascórbico.

Os teores de acidez titulável foram determinados em 10 gramas do suco, que foram diluídos em $50 \mathrm{~mL}$ de água destilada e titulados com $\mathrm{NaOH} 0,01 \mathrm{~N}$, conforme AOAC (1997). Os resultados foram expressos em \% de ácido cítrico.

Os teores de sólidos solúveis foram doseados em gotas de suco extraídas do material 
triturado, quantificado em refratômetro e os resultados foram expressos em porcentagem (\%), conforme AOAC (1997).

Os teores de ácido ascórbico foram determinados por titulação usando-se 2,6dichorophenolindophenol (Rangana, 1977). Pesouse 5 gramas de suco que foram homogeneizadas com ácido oxálico $0,5 \%$. Completou-se o volume do balão volumétrico de $50 \mathrm{~mL}$ com ácido oxálico. Para a titulação pipetou-se $20 \mathrm{~mL}$ do extrato. Utilizou-se como ácido ascórbico como solução padrão $(50 \mu \mathrm{g}$ $\mathrm{mL}^{-1}$ ). Os resultados foram expressos em $\mathrm{mg}$ de ácido ascórbico $100 \mathrm{~g}^{-1}$ de suco.

\section{Resultados e discussão}

Avaliação do material vegetal no campo: do plantio a colheita

A variedade Amelia apresentou a menor taxa de germinação (81\%), mudas com menor tamanho (peso total, raiz e folha de $1,18 \mathrm{~g}, 0,34 \mathrm{~g} \mathrm{e}$ $0,84 \mathrm{~g}$, respectivamente, e também altura de 15,72 $\mathrm{cm}$ ) (Tabela 1). Estes fatores podem ter influenciado no desempenho deste material no momento da colheita, que apresentou os maiores números de plantas não comercializável $(45,4 \%$ do stande sendo equivalente a 254 plantas (Tabela 2 ).

A variedade 5007 apresentou muda com maior peso de raiz $(0,48 \mathrm{~g})$, maior número de folhas $(6,4)$ e também folhas mais largas $(5,1 \mathrm{~cm})$ (Tabela 1), proporcionando plantas com maior peso fresco momento da colheita $(408,2 \mathrm{~g}$ (Tabela 2).

Por outro lado, a Laucy Brown apresentou menor taxa de reposição após 4 dias do plantio das mudas $(0,53 \%$ (Tabela 1$)$ e a 5010 foi que apresentou a menor taxa de plantas não comercializadas $(33,57 \%$ equivalente a 188 plantas) (Tabela 2).
Avaliação dos produtos minimamente processados

Os teores de acidez titulável e sólidos solúveis dos produtos minimamente processados feitos com o material 5007 apresentaram valores mais altos, quando comparados ao demais tratamentos, que não apresentaram diferenças entre si.

Os produtos minimamente processados obtidos com as variedades Laucy e Laurel apresentaram redução nos teores de acidez titulável durante o período de armazenamento. A diminuição desses teores em produtos minimamente processados acontece devido ao metabolismo normal do $\mathrm{CO}_{2}$ ou em resposta do tecido ao neutralizar a acidez gerada pelo $\mathrm{CO}_{2}$ durante $\mathrm{O}$ processo respiratório (Kader, 1986).

Redução nos teores de acidez titulável de alfaces minimamente processadas também foi relatada por Mattos et al. (2007) também, visto que os ácidos orgânicos também são usados como substrato no processo respiratório, o que foi semelhante ao comportamento observado neste trabalho para Laucy e Laurel.

Os teores de sólidos solúveis apresentaram redução em todos os produtos minimamente processados, o que também foi relatado por Galati et a. (2015) ao trabalhar com alface minimamente processada cultivadas com diferentes doses de silício no campo.

Já quanto aos teores de ácido ascórbico, os produtos minimamente processados dos materiais 5007 e Amélia apresentaram teores maiores que os demais produtos, no sexto dia de armazenamento (Tabela 3), o que pressupõe um melhor produto neste dia.

Tabela 1. Dados de germinação, biométricos e reposição de stand no campo de mudas de diferentes alfaces do tipo americana.

\begin{tabular}{lccccc}
\hline \multicolumn{1}{c}{ Variáveis } & 5007 & 5010 & Amelia & Laucy & Laurel \\
\hline Taxa de germinação (\%) & 95,39 & 97,56 & 81,00 & 98,00 & 98,83 \\
Altura total $(\mathrm{cm})$ & $17,09^{*} \pm 2,14^{* *}$ & $18,03 \pm 1,89$ & $15,72 \pm 2,33$ & $16,15 \pm 1,34$ & $18,35 \pm 1,24$ \\
Altura da folha maior $(\mathrm{cm})$ & $9,23 \pm 1,37$ & $9,79 \pm 0,90$ & $7,39 \pm 0,94$ & $7,33 \pm 0,77$ & $9,21 \pm 0,70$ \\
Largura da folha maior $(\mathrm{cm})$ & $5,08 \pm 1,27$ & $4,21 \pm 0,53$ & $4,25 \pm 0,69$ & $3,01 \pm 0,51$ & $3,29 \pm 0,47$ \\
Número de folhas & $6,40 \pm 0,91$ & $6,27 \pm 0,80$ & $6,40 \pm 1,30$ & $5,07 \pm 0,70$ & $5,73 \pm 0,96$ \\
Tamanho da raiz (cm) & $8,36 \pm 1,13$ & $7,57 \pm 1,64$ & $7,71 \pm 1,96$ & $8,18 \pm 0,94$ & $8,43 \pm 0,89$ \\
Peso Total $(\mathrm{g})$ & $2,38 \pm 0,49$ & $2,44 \pm 0,67$ & $1,18 \pm 0,59$ & $2,11 \pm 0,21$ & $1,76 \pm 0,42$ \\
Peso das folhas $(\mathrm{g})$ & $1,76 \pm 0,38$ & $1,92 \pm 0,7$ & $0,84 \pm 0,49$ & $1,76 \pm 0,15$ & $1,33 \pm 0,26$ \\
Peso da Raiz $(\mathrm{g})$ & $0,48 \pm 0,13$ & $0,46 \pm 0,15$ & $0,34 \pm 0,09$ & $0,35 \pm 0,07$ & $0,37 \pm 0,17$ \\
${ }_{* * *}$ Reposição da muda $\left(\% / \mathrm{n}^{\circ}\right)$ & $1,40(8)$ & $2,68(15)$ & $2,14(12)$ & $0,53(3)$ & $10,53(59)$ \\
\hline
\end{tabular}

* Médias oriundas de quinze mudas de alface para cada tipo ${ }^{* *} \mathrm{DP}$. Desvio padrão da média calculada em quinze repetições para cada tipo. ${ }^{* * *} \mathrm{~A}$ reposição das mudas no campo ocorreu até o quarto dia após o plantio (\%/no de plantas reposta). 
Tabela 2. Matéria fresca (MF) de diferentes partes da planta e números de plantas que não atingiram maturidade comercial de diferentes alfaces americanas no momento da colheita.

\begin{tabular}{lccccc}
\hline \multicolumn{1}{c}{ Variáveis } & 5007 & 5010 & Amelia & Laucy & Laurel \\
\hline Peso Total $(\mathrm{g})$ & $408,19^{*} \pm 99,83^{* *}$ & $357,25 \pm 104,35$ & $377,48 \pm 109,58$ & $389,98 \pm 111,08$ & $335,87 \pm 143,85$ \\
Peso da Raiz $(\mathrm{g})$ & $9,11 \pm 2,20$ & $10,82 \pm 3,06$ & $9,65 \pm 3,44$ & $8,87 \pm 2,58$ & $8,98 \pm 2,33$ \\
Peso da Cabeça $(\mathrm{g})$ & $399,08 \pm 98,78$ & $346,43 \pm 104,18$ & $367,83 \pm 108,06$ & $381,11 \pm 110,21$ & $326,89 \pm 143,23$ \\
${ }^{* \star *} \%$ MF Comercial & 97,77 & 97,00 & 97,44 & 97,73 & 97,33 \\
\% Não Comercial & $39,46(221)$ & $33,57(188)$ & $45,36(254)$ & $40,54(227)$ & $35,00(196)$ \\
\hline
\end{tabular}

*Médias oriundas de quarenta plantas de alface para cada tipo **DP. Desvio padrão da média calculada em quinze repetições para cada tipo. ${ }^{* * *}$ Relação do peço da cabeça (parte comercial) com o peso da planta toda.

Tabela 3. Teores de acidez titulável (\% de ácido cítrico), sólidos solúveis (\%) e ácido ascórbico (mg $100 \mathrm{~g}^{-1}$ de alface fresca) de alfaces do tipo americana minimamente processada em armazenamento a $6{ }^{\circ} \mathrm{C}$ e $95 \%$ UR.

\begin{tabular}{cccccc}
\hline \multicolumn{5}{c}{ Acidez Titulável (\%) } \\
\hline Dia & 5007 & 5010 & Amelia & Laucy & Laurel \\
\hline 0 & $0,056 \pm 0,002^{*}$ & $0,058 \pm 0,011$ & $0,049 \pm 0,006$ & $0,070 \pm 0,014$ & $0,056 \pm 0,002$ \\
2 & $0,054 \pm 0,002$ & $0,068 \pm 0,004$ & $0,053 \pm 0,003$ & $0,053 \pm 0,002$ & $0,056 \pm 0,003$ \\
4 & $0,053 \pm 0,001$ & $0,055 \pm 0,002$ & $0,055 \pm 0,002$ & $0,054 \pm 0,000$ & $0,054 \pm 0,001$ \\
6 & $0,062 \pm 0,016$ & $0,052 \pm 0,001$ & $0,052 \pm 0,001$ & $0,051 \pm 0,003$ & $0,052 \pm 0,001$ \\
\hline \multicolumn{7}{c}{ Sólidos Solúveis (\%) } \\
\hline 0 & $3,5 \pm 0,5$ & $3,8 \pm 0,0$ & $3,5 \pm 0,5$ & $3,8 \pm 0,0$ & $3,9 \pm 0,1$ \\
4 & $3,0 \pm 0,0$ & $3,4 \pm 0,6$ & $3,1 \pm 0,1$ & $3,0 \pm 0,1$ & $3,0 \pm 0,0$ \\
6 & $3,0 \pm 0,0$ & $3,1 \pm 0,0$ & $3,1 \pm 0,0$ & $3,1 \pm 0,2$ & $3,3 \pm 0,1$ \\
\hline 0 & $3,4 \pm 0,6$ & $3,0 \pm 0,0$ & $3,0 \pm 0,0$ & $2,7 \pm 0,5$ & $3,0 \pm 0,0$ \\
\hline 2 & $8,17 \pm 1,01$ & Ácido Ascórbico (mg/100g fresca) & \\
6 & $2,34 \pm 0,12$ & $3,80 \pm 0,47$ & $4,12 \pm 0,34$ & $5,55 \pm 0,69$ & $4,32 \pm 0,00$ \\
6 & $2,14 \pm 0,20$ & $2,21 \pm 0,25$ & $3,31 \pm 0,02$ & $3,25 \pm 0,07$ & $3,61 \pm 0,92$ \\
\end{tabular}

*Desvio padrão da média calculada em três repetições para cada dia de análise.

\section{Conclusões}

As variedades 5007 e 5010 são recomendadas para plantio e processamento mínimo, visto que apresentaram melhor desempenho quanto aos parâmetros avaliados.

\section{Agradecimentos}

Os autores agradecem ao apoio financeiro do MCTI "TED n 14.0030.00/2018".

\section{Referências}

ÁLVARES, V.S.; FINGER, F.L.; SANTOS, R.C.A.; SILVA, J.R.; CASALI, V.W.D. Effect of pre-cooling on the postharvest of parsley leaves. Journal of Food Agriculture \& Environment, v.5, n.2, p.31-34, 2007.

AMARANTE, C.; BANKS, N.H.; GANESH, S. Relationship between character of skin cover of coated pears and permeance to water vapour and gases. Postharvest Biology and Technology, v.21, n.3, p.291-301, 2001. < $\underline{10.1016 / \text { S0925-5214(00)00176-9>. }}$

AOAC.Official Methods of Analysis of the Association of Official Analytical Chemists, vol. 16. Patricia Cunningan, Washington, 1997.

AZEVEDO, A.M.; JÚNIOR, V.C.A.; PEDROSA, C.E.; OLIVEIRA, C.M.; DORNAS, M.F.S.; VALADARES, N.R. Agrupamento multivariado de curvas na seleção de cultivares de alface quanto à conservação pós-colheita. Horticultura Brasileira. v.33, n.3, p.362-367, 2015. < https://doi.org/10.1590/S0102-053620150000300014>.

BIASI, L.A., LIMA, M.R., GABARDO, N.P., SCHMID, M.L., MARTHAUS, P.S., ZAMBON, F.R.A. Competição de cultivares de alface na região metropolitana de Curitiba. Horticultura Brasileira, v.9, n.1, p.14- 15, 1991.

CHITARRA, M. I. F., CHITARRA, A. B. Pós-colheita de frutos e hortaliças: fisiologia e manuseio. Lavras: Ed UFLA, 2005. 785p.

FREITAS-SILVA, O.; MORALES-VALLE, H.; VENÂNCIO, A. Potential of aqueous ozone to control aflatoxigenic fungi in Brazil nuts. ISRN Biotechnology, v.2013, p.1-6, 2013. < https://dx.doi/10.5402/2013/859830>.

GALATI, V.C.; GUIMARA ES, J.E.R.; MARQUES, K.M.; FERNANDES, J.R.D.; CECÍLIO FILHO, A.B.; MATTIUZ. B. Aplicação de silício, em hidroponia, na conservação pós-colheita de alface americana 'Lucy Brown' minimamente processada. Ciência Rural, v.45, n.11, p.1932-1938, 2015. < https://doi.org/10.1590/01038478cr20140334>.

GOMES, T.M.; BOTREL, T.A.; MODOLO, V.A.; OLIVEIRA, R.F. Aplicação de $\mathrm{CO}_{2}$ via água de irrigação na cultura da alface. Horticultura Brasileira, Brasília, v.23, 
n.2, p.316-319, 2005. < https://doi.org/10.1590/S0102$05362005000200031>$.

KADER, A.A. Biochemical and physiological basis for effects of controlled and modified atmospheres on fruits and vegetables. Food Technology, v.40, n.5, p.99-104, 1986.

MATTOS, L.M.; MORETTI, C.L.; CHITARRA, A.B.; PRADO, M.E.T. Qualidade de alface crespa minimamente processada armazenada sob refrigeração em dois sistemas de embalagem. Horticultura Brasileira, v.25, n.4, p.504-508, $2007 . \quad<$ https://doi.org/10.1590/S0102$\underline{05362007000400003>\text {. }}$

RANGANA, S. Manual of analysis fruit and vegetable products. New Delhi, McGraw-Hill, 1997.
SANTI, A.; CARVALHO, M.A.C.; CAMPOS, O.R.; SILVA, A.F.; ALMEIDA, J.L.; MONTEIRO, S. Ação de material orgânico sobre a produção e características comerciais de cultivares de alface. Horticultura Brasileira, v.28, n.1, p.87-90, 2010. <https://doi.org/10.1590/S0102$\underline{05362010000100016>\text {. }}$

TOFANELLI, M.B.D.; FERNANDES, M.S.; CARRIJO, N.S.; MARTINS FILHO, O.B. Levantamento de perdas em hortaliças frescas na rede varejista de Mineiros. Horticultura Brasileira, v.27, n.1, p.116-120, 2009. < https://doi.org/10.1590/S0102-05362009000100024>. 